\title{
RELATED SUBSTANCE METHOD DEVELOPMENT AND VALIDATION OF LOXAPINE SUCCINATE IN CAPSULE DOSAGE FORM BY REVERSE PHASE HIGH-PERFORMANCE LIQUID CHROMATOGRAPHY
}

\author{
KHUSHBU A THAKOR*, PASHA TY \\ Department of Pharmaceutical Chemistry, Parul Institute of Pharmacy and Research, Parul University, Vadodara, Gujarat, India. \\ Email: thakorkhushbu3@gmail.com
}

Received: 25 April 2019, Revised and Accepted: 24 May 2019

\section{ABSTRACT}

Objective: The present study gives a simple, rapid, and accurate stability indicating reverse phase high-performance liquid chromatography method for the determination of loxapine succinate and its related substance (related compound A) in capsule dosage form.

Methods: Loxapine succinate and its related substance were attained on a C18 Purospher star $(250 \mathrm{~mm} \times 4.6 \mathrm{~mm}, 5 \mu \mathrm{m}$ particle size $)$ column at $254 \mathrm{~nm}$ detection wavelength, $1.0 \mathrm{ml} / \mathrm{min}$ as a flow rate, and $10 \mu \mathrm{l}$ injection volume. Water:methanol: Triethylamine: Tetrahydrofuran (50:40:1:10) was used a mobile phase, and column oven temperature was $30^{\circ} \mathrm{C}$.

Results: The resolution between loxapine succinate and known unknown impurities was $>2.0$. The correlation coefficient (0.999) value indicates the linear relationship between the concentration and peak areas. The accuracy study was performed by spiking method. Loxapine succinate was exposed to the stress condition of hydrolysis (acid and base), oxidative, thermal, and photolytic degradation. Loxapine succinate was found to degrade unquestionably in acid and base stress condition and almost stable in oxidative, thermal, and photolytic conditions.

Conclusion: The degradant products were well resolved from leading peak and its related compound A peak and any other unknown peak justifying the stability indicating capability of the method. The developed method was validated as per the ICH guidelines. This method is used for periodic analysis in laboratory.

Keywords: Loxapine succinate, Related substance, Validation, Reverse phase high-performance liquid chromatography, ICH.

(c) 2019 The Authors. Published by Innovare Academic Sciences Pvt Ltd. This is an open access article under the CC BY license (http://creativecommons. org/licenses/by/4. 0/) DOI: http://dx.doi.org/10.22159/ajpcr.2019.v12i7.33746

\section{INTRODUCTION}

Loxapine succinate is a typical antipsychotic drug, member of dibenzoxazepine class and used to cure certain cerebral or mood disorders (such as schizophrenia). Loxapine succinate is a dopamine antagonist and also serotonin 5-hydroxytryptamine 2 blockers. The specific mode of action of loxapine succinate has not established. This drug helps in compressing assault and illusion [1-3]. Loxapine is present in capsules as a succinate salt.

Its IUPAC name is 8-chloro-6-(4-methylpiperazin-1-yl)benzo[b][1,4] benzoxazepine. Its molecular weight is $445.9 \mathrm{~g} / \mathrm{mole}$.

Chemical structure of loxapine succinate is shown in Fig. 1 [4-7].

Impurities will be quantified as known impurity: Loxapine related compound A. Chemical structure of loxapine succinate is shown in Fig. 2.

All other peaks will be considered as unknown impurities [8].

Literature search admits that several methods were reported, namely ultraviolet (UV) method, high-performance liquid chromatography (HPLC) method, HPLC-tandem mass spectrometry, and gas chromatography-mass spectrometry method. However, there was no method reported for related substance. To successfully launch the product and to maintain market revenue, it should meet the therapeutic requirements along with safety for patients who will receive the medicine. For that purpose, we have to analyze the product and for which analytical method is needed. The rationale of the research is that loxapine succinate contains the degradant impurity, and our goal is to separate the degradant impurity with the main peak of loxapine succinate and it should not interfere with any other peak. Hence, there is a demand for developing related substance method for loxapine succinate in capsule dosage form. Hence, the authors made an endeavor to develop simple, accurate, sensitive, selective, and specific-related substance method for determination of loxapine succinate in capsule dosage form [9-24].

\section{MATERIALS AND METHODS}

\section{Chemicals and reagents}

Loxapine succinate was granted as a gift sample by Hetero drugs Ltd, Hyderabad, Andhra Pradesh, India. Capsule dosage form was bought up from local pharmacy. All the chemicals and reagents such as methanol, acetonitrile, and water were of HPLC grade and were procured from Merck Specialties Pvt. Ltd., Mumbai, India.

\section{Instrumentation}

HPLC waters Alliance 2695 series equipped with autosampler, temperature control, and autoinjector with capacity to inject $5 \mu \mathrm{l}-500 \mu \mathrm{l}$ with PDA detector. Waters HPLC system is equipped with Empower 2 software finally optimized chromatographic condition is shown in Table 1.

\section{Methods}

Preparation of diluted standard solution

Accurately weighed and transferred $60 \mathrm{mg}$ of loxapine succinate standard into $200 \mathrm{ml}$ volumetric flask. Add diluents about $70 \%$ of flask volume and sonicate to dissolve the solution. Volume was made up to mark with diluents. Pipette out $5 \mathrm{ml}$ of stock solution into $50 \mathrm{ml}$ volumetric flask and volume made up to mark with diluents. Again 
pipette out $5 \mathrm{ml}$ of stock solution into $50 \mathrm{ml}$ volumetric flask and volume made up to mark with diluents $(3 \mu \mathrm{g} / \mathrm{ml})$. Chromatogram of diluted standard $(3 \mu \mathrm{g} / \mathrm{ml})$ is shown in Fig. 3. Characterization of peak of diluted standard is shown in Table 2.

\section{Related compound A stock}

Accurately weighed and transferred $3 \mathrm{mg}$ of related compound A into $20 \mathrm{ml}$ volumetric flask. Add $5 \mathrm{ml}$ of diluents and sonicate to dissolve the solution and volume made up to mark with diluents.

Spiked sample (Loxapine $1500 \mu \mathrm{g} / \mathrm{ml}$, ImpA 3 $\mathrm{gg} / \mathrm{ml}$ )

Accurately weighed and transferred loxapine succinate equivalent to $75 \mathrm{mg}$ of loxapine into $50 \mathrm{ml}$ volumetric flask. Add $1 \mathrm{ml}$ of related compound A stock solution. Add diluent about $50 \%$ of flask volume. Sonicate for $30 \mathrm{~min}$ with intermittent shaking, volume made up to mark with diluent. Solution filter using $0.45 \mu \mathrm{m}$ Polyvinylidene fluoride filter after $5 \mathrm{ml}$ of filtrate discarded. Chromatogram of Spiked sample is shown in Fig. 4. Characterization of peak of sample spiked with known impurity is shown in Table 3.

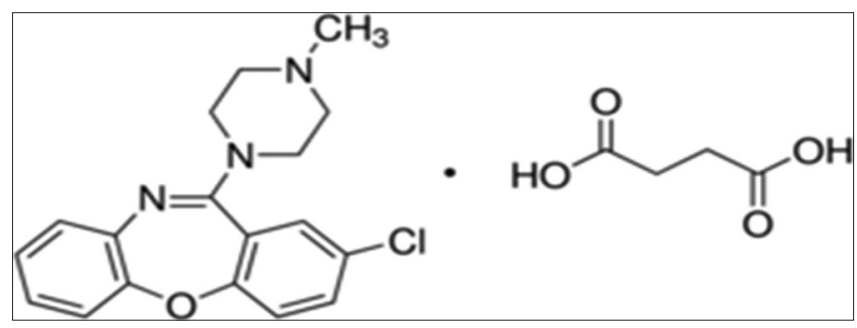

Fig. 1: Chemical structure of loxapine succinate

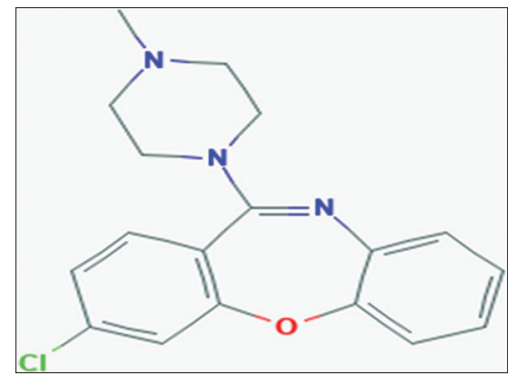

Fig. 2: Chemical structure of loxapine related compound A

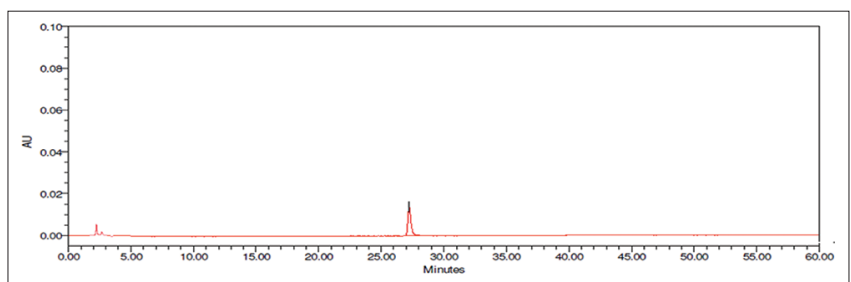

Fig. 3: Chromatogram of diluted standard ( $3 \mu \mathrm{g} / \mathrm{ml})$

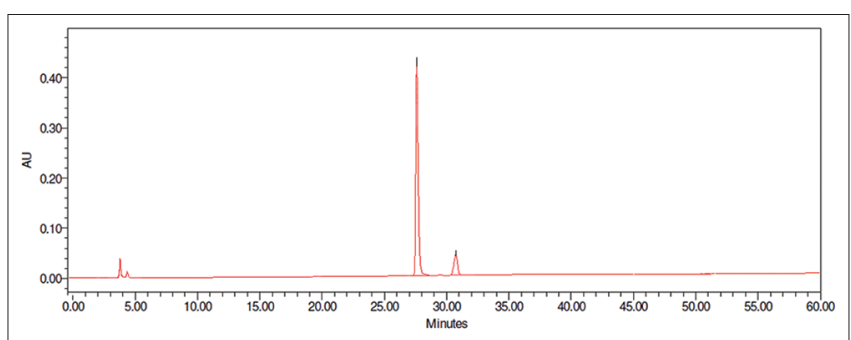

Fig. 4: Chromatogram of spiked sample

\section{RESULTS AND DISCUSSION}

Validation of the method

The described method has been validated for the loxapine succinate and related compound A by HPLC determination as per the ICH guidelines.

\section{Specificity and mass balance study}

All forced degradation samples were analyzed at an initial concentration of $1500 \mu \mathrm{g} / \mathrm{ml}$ of loxapine succinate to ensure the homogeneity and purity of peak. The forced condition used for degradation studies was acid degradation $(10 \mathrm{ml} 1 \mathrm{~N} \mathrm{HCl}$, RT for $5 \mathrm{~h}$ ), base degradation ( $10 \mathrm{ml} 0.1 \mathrm{~N} \mathrm{NaOH}$, RT for $5 \mathrm{~h}$ ), oxidation $\left(10 \mathrm{ml} 30 \% \mathrm{H}_{2} \mathrm{O}_{2}\right.$, RT for $\left.5 \mathrm{~h}\right)$, thermal $\left(85^{\circ} \mathrm{C}\right.$ for 7 days $)$, and photolytic degradation (1.2 million lux hours of UV light 200 watt $\mathrm{h} / \mathrm{m}^{2}$ for 7 days). Very significant degradation of loxapine succinate was observed in acidic and basic stress condition leading to the

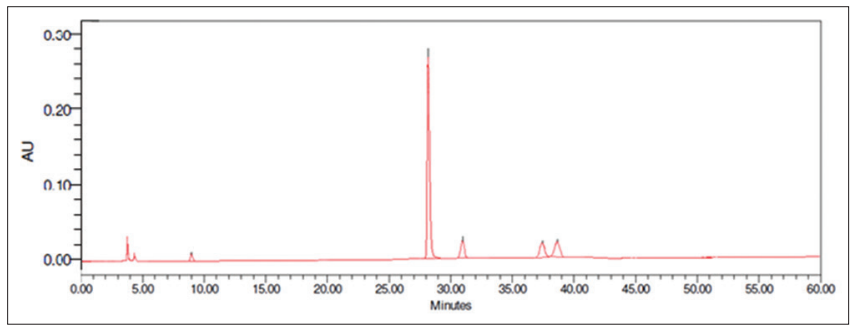

Fig. 5: Acid degradation sample chromatogram

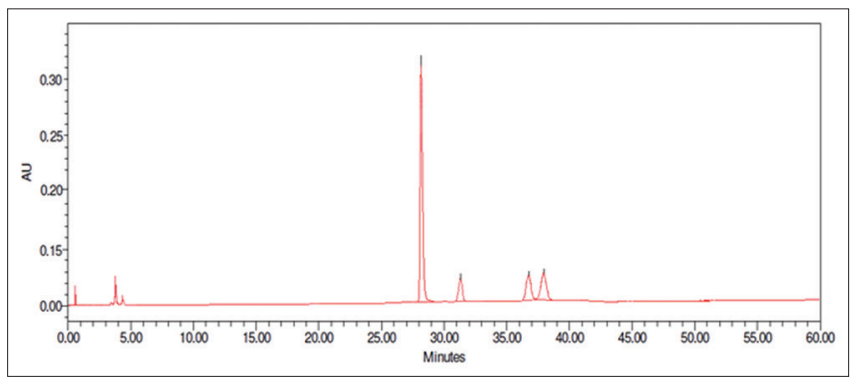

Fig. 6: Base degradation sample chromatogram

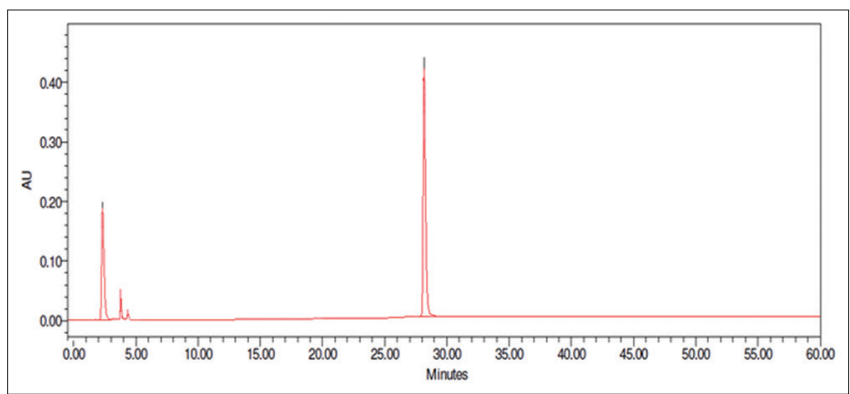

Fig. 7: Peroxide degradation sample chromatogram

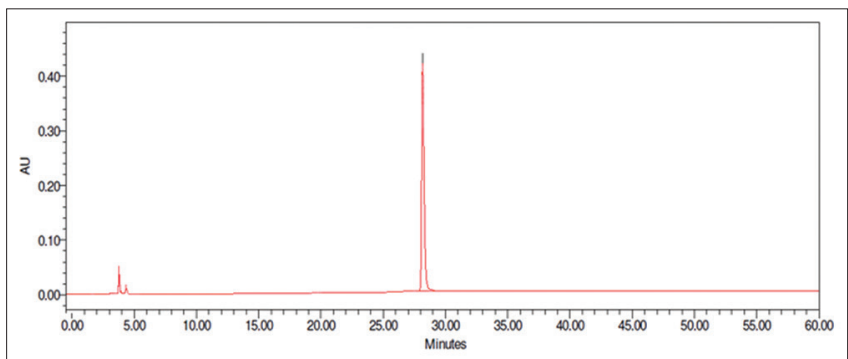

Fig. 8: Thermal degradation sample chromatogram 


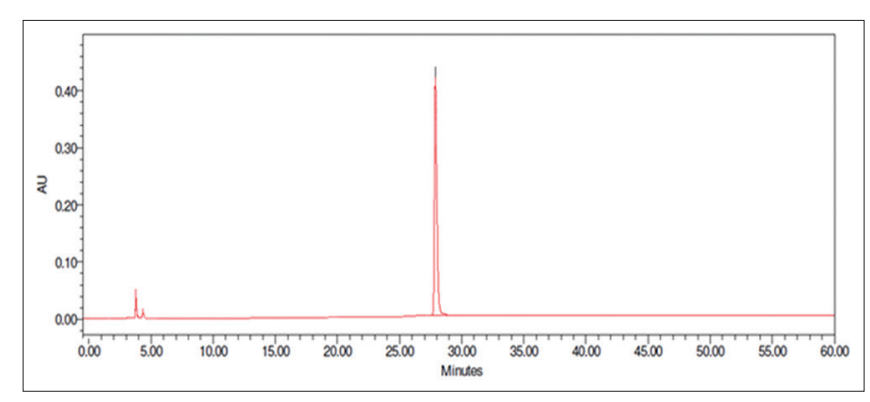

Fig. 9: Photolytic degradation sample chromatogram

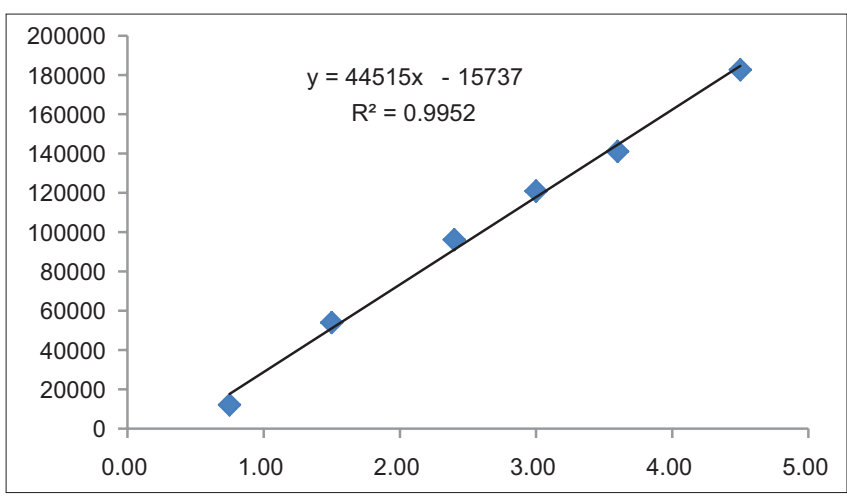

Fig. 10: Calibration curve of Loxapine succinate

Table 1: Optimized chromatographic conditions

\begin{tabular}{ll}
\hline Parameter & Recommendation \\
\hline Column & $\begin{array}{l}\mathrm{C}_{18} \text { Purospher star }(250 \mathrm{~mm} \times 4.6 \mathrm{~mm}), 5 \mu \mathrm{m} \\
\text { particle size }\end{array}$ \\
Column temperature & $30^{\circ} \mathrm{C}$ \\
Mobile phase & Water: methanol: TEA: THF: $50: 40: 1: 10 \mathrm{ml}$ \\
Flow rate & $1.0 \mathrm{~mL} / \mathrm{min}$ \\
Injection volume & $10 \mu \mathrm{L}$ \\
Detection wavelength & $254 \mathrm{~nm}$ \\
Sampler temperature & Ambient \\
Diluent & Mobile phase \\
\hline
\end{tabular}

TEA: Triethylamine, THF: Tetrahydrofuran formation of loxapine related compound A. Significant degradation was observed in oxidative, thermal, and photolytic stress conditions. Chromatograms of sample degradation are shown in Figs. 5-9. Mass balance result was calculated for all stressed samples and found to between $95 \%$ and $102 \%$. The purity angle was within the purity threshold limit obtained in all the stressed samples and gives the analyte peak homogeneity. Results of mass balance calculation are presented in Table 4.

\section{Linearity and range}

A series of solutions of loxapine related compound A ranging from limit of quantitation (LOQ) to $150 \%$ of specification level were prepared and injected into HPLC system. The linearity of the method was established by the plotting a graph between the concentration and response of loxapine related compound $\mathrm{A}$. The results of the linearity study are presented in Table 5. It shows that the $r^{2}$ is more than 0.990. The relative response factor (RRF) is used to control impurities in drug substance and drug product. It used to correct the differences in detector response of impurities with analyte peak. RRF is established by slope method with linear range of solution and found to be 2.685. Calibration curve of loxapine succinate is shown in Fig. 10.

\section{Accuracy}

Accuracy of an analytical procedure expresses the closeness of agreement between the true value and the value found. The accuracy of the method is established in terms of recovery. Sample solution for accuracy study was prepared in triplicate by spiking the impurities at the specification level (not more than $0.2 \%$ of each impurity) to the test sample at LOQ, $50 \%, 100 \%$, and $150 \%$ of the specification level and injected into the HPLC system. Individual recovery, mean recovery, and percentage relative standard deviation (\% RSD) at each level are presented in Table 6. Recoveries were found to be within the range of $90 \%-110 \%$ and meet with the ICH guidelines.

\section{Precision}

To evaluate the method precision for related substance, six replicates of test preparations $(n=6)$ of loxapine succinate were prepared and spiked known impurity at specification level and analyzed as per method. Percentage impurity calculated and reported in Table 7. \% RSD values were found within the limits. The intermediate precision of the method was evaluated by adopting the same method using

Table 2: Characterization of peak of diluted standard

\begin{tabular}{llllll}
\hline Peak name & RT ( $\mathrm{min})$ & Area $(\%)$ & Tailing factor & Purity angle & Purity threshold \\
\hline Loxapine succinate & 26.541 & $50,135(100)$ & 1.5 & 0.781 & 1.421 \\
\hline
\end{tabular}

RT: Retention time

Table 3: Characterization of peak of sample spiked with known impurity

\begin{tabular}{|c|c|c|c|c|c|c|}
\hline Peak name & RT (min) & Area (\%) & Tailing factor & USP resolution & Purity angle & Purity threshold \\
\hline Loxapine succinate & 26.654 & $24,670,304(99.52)$ & 1.7 & - & 1.974 & 2.198 \\
\hline Loxapine related compound A (impurity) & 31.099 & $119,782(0.48)$ & 1.0 & 3.9 & 1.294 & 1.329 \\
\hline
\end{tabular}

RT: Retention time, USP: United states pharmacopeia, A: Impurity

Table 4: Forced degradation study-percentage impurity with mass balance (drug product)

\begin{tabular}{llllll}
\hline Sample name & Purity angle & Purity threshold & Total impurities (\%) & Percentage assay & Mass balance (\%) \\
\hline Control & 1.974 & 2.198 & 0.0 & 99.5 & NA \\
Acidic & 2.045 & 2.185 & 10.25 & 90.95 & 101.70 \\
Basic & 1.875 & 2.095 & 10.16 & 92.83 & 103.50 \\
Peroxide & 1.836 & 1.946 & 0.0 & 94.81 & 95.28 \\
Thermal & 2.010 & 2.184 & 0.0 & 98.36 & 98.85 \\
Photolytic & 2.326 & 2.651 & 0.0 & & 98.45 \\
\hline
\end{tabular}

NA: Not available 
Table 5: Linearity data of loxapine related compound A

\begin{tabular}{ll}
\hline Concentration $(\boldsymbol{\mu g} / \mathrm{ml})$ & Area \\
\hline 0.75 & 12,089 \\
1.50 & 53,989 \\
2.40 & 96,094 \\
3.00 & 120,872 \\
3.60 & 141,087 \\
4.50 & 182,564 \\
\hline
\end{tabular}

Table 6: Accuracy results

\begin{tabular}{|c|c|c|c|c|}
\hline \multicolumn{5}{|c|}{ Related Compound A } \\
\hline Level & Concentration & Area & Percentage recovery & Mean \\
\hline \multirow[t]{3}{*}{ LOQ } & 0.75 & 12,085 & 99.1 & 100.1 \\
\hline & & 12,219 & 100.2 & \\
\hline & & 12,309 & 101.0 & \\
\hline \multirow[t]{3}{*}{$50 \%$} & 1.5 & 59,134 & 98.57 & 99.3 \\
\hline & & 59,321 & 98.89 & \\
\hline & & 60,266 & 100.46 & \\
\hline \multirow[t]{3}{*}{$100 \%$} & 3.0 & 121,876 & 100.83 & 100.9 \\
\hline & & 121,331 & 100.38 & \\
\hline & & 122,819 & 101.61 & \\
\hline \multirow[t]{3}{*}{$150 \%$} & 4.5 & 180,875 & 99.07 & 99.3 \\
\hline & & 181,129 & 99.21 & \\
\hline & & 182,088 & 99.74 & \\
\hline
\end{tabular}

LOQ: Limit of quantitation different column, different HPLC system, and different days and results are enlisted in Table $8 . \%$ RSD values were found to be within the limits.

\section{Limit of detection (LOD) and LOQ}

LOD and LOQ for related substance are determined by injecting a series of solution of known concentration till the signal-to-noise ratio became as 3:1 and 10:1, respectively, and results are summarized in Table 9. The LOD and LOQ values were determined as $0.225 \mu \mathrm{g} / \mathrm{ml}$ and $0.75 \mu \mathrm{g} / \mathrm{ml}$ for loxapine related compound $\mathrm{A}$.

\section{Robustness}

The robustness of method was studied by injecting the blank and standard with willfully changes in flow rate of mobile phase, change in wavelength, and change in column temperature. The results of the robustness are given in Table 10. Results showed that method is not affected by intentionally changes in method parameters which was proved by $\%$ RSD of three replicates of standards $<2$.

\section{CONCLUSION}

A specific, precise, linear, and accurate stability indicating HPLC method has been developed for the quantification of loxapine succinate related compound A. The method has been validated for specificity, stability, linearity, range, accuracy, precision, and robustness. This method is able to quantify all known impurities in the presence of other unknown impurities within specification limit. As the method is validated in accordance with ICH Q2(R1) guideline, it could be taken up for the

Table 7: Method precision results

\begin{tabular}{|c|c|c|c|c|c|}
\hline \multirow[t]{2}{*}{ Precision set } & \multirow[t]{2}{*}{ Spiked concentration } & \multicolumn{2}{|c|}{ Loxapine } & \multicolumn{2}{|c|}{ Related Compound A } \\
\hline & & Area & Percentage impurity & Area & Percentage impurity \\
\hline 1 & 3 & 51,476 & 0.21 & 124,084 & 0.21 \\
\hline 2 & 3 & 52,341 & 0.21 & 122,765 & 0.20 \\
\hline 3 & 3 & 49,231 & 0.20 & 120,334 & 0.20 \\
\hline 4 & 3 & 48,976 & 0.20 & 122,367 & 0.20 \\
\hline 5 & 3 & 51,324 & 0.21 & 121,432 & 0.20 \\
\hline 6 & 3 & 51,768 & 0.21 & 120,036 & 0.20 \\
\hline Average & & & 0.20 & & 0.20 \\
\hline SD & & & 0.01 & & 0.00 \\
\hline$\%$ RSD & & & 2.8 & & 1.3 \\
\hline
\end{tabular}

SD: Standard deviation, \% RSD: Percentage relative standard deviation

Table 8: Intermediate precision results

\begin{tabular}{|c|c|c|c|c|c|}
\hline \multirow[t]{2}{*}{ Precision set } & \multirow[t]{2}{*}{ Spiked concentration } & \multicolumn{2}{|c|}{ Loxapine } & \multicolumn{2}{|c|}{ Related Compound A } \\
\hline & & Area & Percentage impurity & Area & Percentage impurity \\
\hline 1 & 3 & 51,486 & 0.22 & 124,084 & 0.22 \\
\hline 2 & 3 & 51,674 & 0.21 & 122,765 & 0.20 \\
\hline 3 & 3 & 50,364 & 0.22 & 120,334 & 0.22 \\
\hline 4 & 3 & 49,683 & 0.21 & 122,367 & 0.21 \\
\hline 5 & 3 & 51,987 & 0.20 & 121,432 & 0.20 \\
\hline Average & & & 0.21 & & 0.21 \\
\hline SD & & & 0.008 & & 0.009 \\
\hline$\%$ RSD & & & 4.2 & & 4.6 \\
\hline
\end{tabular}

SD: Standard deviation, \% RSD: Percentage relative standard deviation

Table 9: Limit of detection limit of quantitation confirmation

\begin{tabular}{|c|c|c|c|c|}
\hline Name & LOD concentration $(\mu \mathrm{g} / \mathrm{ml})$ & $\mathrm{S} / \mathrm{N}$ ratio & LOQ concentration $(\mu \mathrm{g} / \mathrm{ml})$ & $\mathrm{S} / \mathrm{N}$ ratio \\
\hline Loxapine Related Compound A & 0.225 & 4 & 0.75 & 12 \\
\hline
\end{tabular}

LOQ: Limit of quantitation, LOD: Limit of detection, S/N: Signal to noise 
Table 10: Robustness results

\begin{tabular}{|c|c|c|c|c|}
\hline \multirow[t]{2}{*}{ S.No. } & \multirow[t]{2}{*}{ Robustness parameter } & \multicolumn{3}{|c|}{ Loxapine succinate } \\
\hline & & $\%$ RSD & Tailing factor & Theoretical plates \\
\hline 1 & Low flow $(0.8 \mathrm{ml} / \mathrm{min})$ & 1.1 & 1.4 & 12,553 \\
\hline 3 & Low wavelength (252 nm) & 1.2 & 1.5 & 12,344 \\
\hline 4 & High wavelength (256 nm) & 1.0 & 1.0 & 13,879 \\
\hline 5 & Low column temperature $\left(28^{\circ} \mathrm{C}\right)$ & 1.4 & 1.2 & 12,984 \\
\hline 6 & High column temperature $\left(32^{\circ} \mathrm{C}\right)$ & 0.9 & 1.3 & 23,786 \\
\hline
\end{tabular}

\% RSD: Percentage relative standard deviation

analysis of related substance in the dosage form of loxapine succinate in pharmaceutical industries.

\section{AUTHORS' CONTRIBUTION}

The authors express sincere thanks to Hetero drugs Ltd, Hyderabad, Andhra Pradesh, India, for providing a gift sample of loxapine succinate and Umedica Pvt. Ltd., Vapi, Gujarat, for providing necessary facilities to carry out the research work.

\section{CONFLICTS OF INTEREST}

The authors reveal that there are no conflicts of interest.

\section{REFERENCES}

1. Barar FS. Essentials of Pharmacotherapeutics. $5^{\text {th }}$ ed. New Delhi: S. Chand and Company Ltd.; 2011. p.143.

2. Tripathi KD. Essential of Medical Pharmacology. $5^{\text {th }}$ ed. New Delhi: Jaypee Publisher; 1997. p. 394.

3. Hawland RD. Reviews: Pharmacology. $3^{\text {rd }}$ ed. Philadelphia, PA: Lippincott's Illustrated Reviews, B. I. Publications; 1996. p. 149.

4. Available from: http://www.drugbank.ca/drugs/DB00408. [Last accessed on 2019 Apr 13]

5. Available from: http://www.chemspider.com/chemicalstructure.3827. html. [Last accessed on 2019 Apr 15].

6. Available from: http://Pubchem.ncbi.nlm.nih.gov/compound/Loxapine. [Last accessed on 2019 Apr 11].

7. Available from: http://www.rsc.org/merck-index. [Last accessed on 2019 Apr 18].

8. The United State Pharmacopoeia Convention. $<905>$ US Pharmacopeia 32 NF 27. Vol. 1. Rockville: The United State Pharmacopoeia Convention; 2005. p. 2817

9. International Conference on Harmonisation. The International Council for Harmonisation of Technical Requirements for Pharmaceuticals for Human Use Guidelines. Geneva, Switzerland: Stability Testing of New
Drug Substance and Products; 2003.

10. ICH Q2A. Validation of Analytical Method, November 2012; 2005

11. ICH Q8 (R2). Pharmaceutical Development; 2009.

12. ICH Q9. Quality Risk Management; 2005.

13. ICH Q10. Pharmaceutical Quality System; 2008.

14. Ahuja S, Scypinski S. Handbook of Modern Pharmaceutical Analysis United States of America: Academic Press; 2001. p. 349.

15. Rajendra P, Tushar D. Review on analytical method development and validation. J Pharm Anal 2014;3:1-10.

16. Skoog DA, Holler FJ. Nieman TA. An Introduction to Analytical Chemistry. $5^{\text {th }}$ ed. Singapore: Thomson Brooks/Cole Publication; 1994. p. $566-8$.

17. Sharma BK. Instrumental Methods of Chemical Analysis. $23^{\text {rd }}$ ed. New Delhi: Goel Publication House; 2002. p. 1-16.

18. Jeffery G, Bassett J, Mehdham J, Denney R. In Text of quantitative Chemical Analysis. $5^{\text {th }}$ ed. Harlow, Essex, England, New York: Longman Scientific \& Technical, Wiley; 1989. p. 34.

19. Snyder L, Kirkland J. Introduction to Modern Liquid Chromatography. $2^{\text {nd }}$ ed. New York: John Wiley \& Sons Inc.; 1997. p. 267-400.

20. U.S. Department of Health and Human Services Food and Drug Administration. Guidance for Industry: Analytical Procedures and Methods Validation of Drugs and Biologics. U.S. Department of Health and Human Services Food and Drug Administration; 2015. p. 1-13.

21. Bakshi M, Singh S. Development of validated stability-indicating assay methods - critical review. J Pharm Biomed Anal 2002;28:1011-40.

22. Bhojan C. Development of UV spectrophotometry and HPTLC techniques for loxapine in formulation. Int $\mathrm{J}$ Chem Pharm Anal 2017;4:12-7.

23. Dammalapati S, Rudraraju R. Development and validation of RPHPLC method for loxapine in capsule dosage form. Int J Adv Pharm Anal 2015;5:61-4

24. Garay Garcia L, Forfar-Bares I, Pehourcq F, Jarry C. Simultaneous determination of four antipsychotic drugs in plasma by highperformance liquid chromatography. Application to management of acute intoxications. J Chromatogr B Analyt Technol Biomed Life Sci 2003;795:257-64. 